\title{
'They haven't a clue!' A qualitative study of staff perceptions of 11-14 year-old female clinic attenders
}

Linda Mason Centre for Research in Healthcare, Liverpool John Moores University, Liverpool, England, UK

Against a background of decreasing age at sexual debut, local Brook staff voiced concerns about the increase in clinic attenders under the age of 14 years, who appeared to engage in risky behaviours. This exploratory study, carried out with service providers in a young persons sexual health clinic, aimed to discover what issues staff felt were important to 11-14 year-old girls, in order that a future study be conducted with the young girls themselves. Service providers from two Brook Advisory Centres were interviewed. The interviews were semi-structured and analysed using content analysis. Many of the issues that staff identified as important to young girls mirrored current research findings with older adolescents. These were: alcohol consumption, peer pressure, low self-esteem and confidence, and a lack of knowledge around sexually transmitted infections. However, a new issue to emerge was the high proportion of young girls attending the clinic for the emergency contraceptive pill despite not knowing whether they had had intercourse or not. The study also found that staff perceived the need to understand issues from the perspective of the young girls themselves.

Staff identified a necessity for improved sex education and education around peer pressure and assertiveness, whilst topics for future research which emerged from the study findings included issues of self-esteem, dynamics of peer/media pressure and why young girls feel that they need to have sex.

Key words: alcohol consumption; risk taking; sexual health; young girls

\section{Introduction}

Across England and Wales there has been a marked decrease in age at first intercourse since 1990 (Wellings, 2001). A study carried out in schools across one health authority in England found that $11 \%$ of 13 -year olds (boys and girls) had already had full sexual intercourse (Burrack, 1999). Against this background, much research has been carried out into young peoples sexual behaviour, yet there are still a number of gaps in the knowledge base, particularly pertaining to the early adolescent. Where studies have included young participants, there is a tendency to group them simultaneously with slightly older age groups.

Address for correspondence: Linda Mason, Centre for Research in Health Care, Liverpool John Moores University, Liverpool L2 2ER, England, UK. Email: Healmas2@livjm.ac.uk
For example, many studies have used all college/school pupils for their sample (Burrack, 1999; Van den Akker et al., 1999; Topolski et al., 2001). Few have focused only upon the very young adolescent, yet it could be argued that comparing the needs of 11-year old girls with those aged 15 years for example, might be completely inappropriate. Whilst individuals reach physical, cognitive and emotional maturation at differing ages, in general the maturity of 11-year olds would be expected to differ qualitatively from that of their 15-year old peers or siblings. In light of the decreasing age at first sexual experience, it might be prudent to concentrate future research around the needs and experiences of the younger adolescent.

A further limitation of the research literature is that it makes few distinctions between boys and girls, yet it is known that adolescents of the same age and educational status have both disparate 
experiences and knowledge of a sexual nature (De Gaston et al., 1996; Van den Akker et al., 1999; Nahom et al., 2001). According to Brook Advisory (2002) the age at which young people report their first experience of sex is 14 years for women and 13 years for men. However, women are more likely to regret it afterwards, feel pressured into having intercourse and worry more about pregnancy (De Gaston et al., 1996).

The present exploratory study came about following discussions with staff from one of the Brook Advisory Centres who are concerned that young girls (i.e., those 14 years and under) appear to be taking risks with their physical and psychological health through their sexual behaviour. Limited research has been undertaken on health professionals' views of young people's sexuality and behaviour, although a couple of earlier studies have shown that professionals are uncomfortable in dealing with adolescent sexuality (Matocha and Waterhouse, 1993; Blum et al., 1996). One study of providers of young people's sexual health care (Pitts et al.,1996: p. 1) concluded that 'all providers tended to hold negative views of young people and their sexual activity', yet as Porter (2002) argues, these health care professionals have the 'opportunities to begin to understand and facilitate early adolescent females healthy sexual development'. The research objective of this study was therefore to explore issues that staff felt were pertinent to their young female clients. It is intended that these findings will be used in the future as a focal point for a series of qualitative interviews with the young girls themselves.

\section{Method}

\section{Study participants}

The managers of two Brook Centres in the north-west of England were contacted and permission obtained to interview their staff. One of the centres is based in a major city centre which sees a broad range of clients, not only from the city, but also neighbouring towns and suburbs. The other centre is based in a small town service with a mixed population. Whilst there are areas with high deprivation, there are also pockets of wealth and this is reflected in their client population.

Staff were selected mainly on the basis of availability from the clinic, although a mix of both counselling and nursing staff was requested. A quota was not decided at the outset. Instead, the number of participants was determined through balancing the level of disruption to the clinics with the need to provide enough information to satisfy the research agenda. It was striking that similar stories and opinions became evident with the addition of each new participant. Data collection thus stopped after eight interviews as saturation point was deemed to have occurred. Altogether three counsellors and five nurses participated in the study. All were female and had worked at a Brook Centre for between two and a half and 11 years.

\section{The interviews}

The face-to-face interviews were conducted in the clinic. An interview guide was developed encompassing the following topics:

1) Reasons for young girls accessing the service

2) Risk taking behaviour

3) Priority areas for future work.

However, within these, the semi-structured format enabled respondents to highlight those issues they felt to be important, and allowed for probing and clarifying questions to yield more accurate and in-depth responses. The guide was checked for validity by a health practitioner who worked in the field of family planning.

Throughout the interviews it was stressed that the questions related only to their 11-14 year-old female clients. The interviews lasted from $30 \mathrm{~min}-$ utes to one hour and 10 minutes. All interviews were tape recorded and transcribed verbatim immediately following the interview. All transcripts were subsequently checked against the tape recordings to ensure accuracy.

\section{Analysis}

Content analysis was used to explore the issues emerging (Weber, 1990). This was undertaken solely by the author of the study. First, each transcript was read through twice to develop an understanding with the text as it was written verbatim, and also for familiarity. The first transcript was then studied in detail, with the text searched for major themes and subcategories. Once identified, each theme and subcategory was coded with a subheading which described the phenomena in question. These were noted on file. The second transcript was 
scrutinized in the same manner, and any new theme or subcategory was coded and added to the file. Recurring themes and subcategories were given the same code as previous and added to the appropriate section on the file. The process continued until all eight transcripts had been scrutinized in this manner. The data under each subheading was then analysed. This involved making judgements about the number of participants who mentioned each topic, and also the frequency that the topic occurred. Comparisons and contradictions were sought. The language used was also explored for repetitions, use of exclamations and adjectives to denote intensity of feelings, attitudes and expressions, local dialects and cultural norms. Those phenomena that were mentioned with greater frequency and with greater intensity were accorded more importance. The findings thus far were written as a preliminary draft text. Each transcript was then reread, to ensure that the findings had not been misrepresented in any way, and that the quotes had not been taken out of context. Any additional issues that had not been covered thus far were also added. The text was then read again and amendments made as necessary.

\section{Results}

Four core issues emerged from the interviews:

- Unplanned sex following alcohol consumption

- Peer pressure

- A lack of self-assertiveness

- A lack of knowledge around sexually transmitted infections (STIs).

The importance of these issues was highlighted by the similarities of both content and language that were evident within the narratives, and also by the way that all interviewees spoke of these issues repeatedly without being prompted.

\section{Unplanned sex}

Staff identified a pattern whereby some young girls come to Brook requesting the morning after pill. This results from their having had unplanned sex as a consequence of having consumed too much alcohol. As a consequence, narratives told of girls confiding in the staff that they were uncertain as to whether they had actually had sex or not. The frequency and similarity of the following quotes demonstrate that the staff feel that they are hearing the same story over again, indeed 'this happens every single week' (Interview 4) and that this is a major issue for these young girls:

who found themselves devastated, never planned to be in this situation, went to a sleepover and things got out of hand, had too much to drink, something happened, not really quite sure what happened.

(Interview 2)

Sometimes they don't know if they've had it because they've been drinking, and they haven't a clue, so they'll come in on a Monday to have the morning after pill. Just in case. They say 'I don't know whether I've had sex but just in case'.

(Interview 8)

Now this is the most common one. They'll come in and go 'I don't know if I've actually had sex or not, but when I woke up my knickers were off or something and I feel a bit sore'. And that's the most typical one we get, where they don't know, they've trusted somebody and that's it, they don't know what they've done.

(Interview 7)

All staff identified alcohol consumption as the major precipitating factor for having unplanned sexual activity,

Alcohol is the biggest reason for young girls to get in sexual activity, whether it's wanted or not.

(Interview 7)

When asked what were the other issues affecting their young clients, every interviewee spoke of 'pressure'. Indeed one described the pressure which young girls were faced with as 'horrendous' (Interview 1). Peer pressure was identified as coming predominantly from female friends:

I think it's girls. I do. But I think that the girls when they're talking they're pressurising each other, it's a bit of a dare. I think it must be a dare sometimes to them and then it gets out of hand.

(Interview 7) 
This was identified as a more common and stronger influence than pressure from boyfriends. Just three of the eight interviewees mentioned that boyfriends put pressure on young girls to have sex with them, or that girls felt pressure to have sex to stop their boyfriend from leaving. However, the media, particularly teenage magazines, and soap operas, were identified as major culprits by most of the staff.

The following quotes illustrate the staff's perceptions of the pressure and their belief that clients are unable to counteract it. They suggest that whilst sex may be voluntary it is often unwanted:

They probably feel they don't want to but they do cause that's what the norm is. That's what their mate's do, that's what they talk about.

(Interview 8)

They feel they're not normal if they don't, if they feel they're not normal then that's a problem. Unless they have sex they think they're in then, and they feel normal.

(Interview 2)

At some point they ought to be doing it, and I use the word ought not because they want to necessarily but they feel they ought to be doing it.

(Interview 1)

The interviewees stated that a consequence of being pressured into having sex is that 'they say they haven't enjoyed it' (interview 5) and come to regret it afterwards:

And they're full of tremendous regret and all the rest of it, that they've actually had an episode of sex and they're not dirty and feel ashamed of themselves.

\section{(Interview 7)}

And a lot of the time they'll regret it. They do, the 13-year olds, the young ones in particular can regret it after.

(Interview 2)

However, despite any regret, staff were puzzled and concerned that it did not seem to stop girls from repeating their behaviour, which seemed to them to be the rational course of action. When asked why, one interviewee stated:

It's their image of themselves as well as other people's image of them, that once they've been - I use the term abused - they're fair game. And in their own eyes they're fair game.

(Interview 2)

This leads to the next major theme selfassertiveness/self-esteem. All staff believed these girls were unable to resist pressure because they lacked such qualities. Both terms were used frequently throughout the interviews and perceived to be a common character trait lacking in their younger clients:

I think assertiveness, cause they're, really it's a shame cause they do lack confidence, they do lack the ability to say no to people. It's as thought they have to be pleasing all the time. And in there, there's a little individual who is fighting against everything but doesn't have the ability to say 'no I don't want this'.

(Interview 4)

You know, their self esteem is low, their empowerment, they have no.... If fella's want sex with them they'll have sex ... and it's this attitude that they've got that if they're asked to have sex they'll have sex.

(Interview 2)

A lack of knowledge regarding sexually transmitted infections, including human immunodeficiency virus (HIV), also emerged as a dominant theme throughout. The consensus of opinion was that young girls were completely ignorant about the dangers of having early or unprotected sex, and had no concept that they personally might pick up an infection. Rather than knowingly ignoring the risk, staff believed that young girls were unaware that they might be putting themselves at risk:

They haven't a clue! You mention infection and they go 'oh'? Cause all they're worrying about is pregnancy.

(Interview 1)

Infections don't play a part in their brain at all!

(Interview 7)

You talk to them about infections and stuff and it's as though you are talking a foreign language to them.

(Interview 8) 
The exception to this was chlamydia which had been the subject of a high profile pilot scheme to look at ways of screening young people in an area serviced by one of the Brook Centres. Consequently young people there were believed to have a wider knowledge base.

\section{The way forward}

Staff identified two broad areas around information and education. These were:

- sex education

- assertiveness training.

With respect to sex education it was thought that a lot more in-depth education was needed around the biology and physiology of reproduction. Many clients displayed 'ignorance' (Interview 6) of their own bodies, 'they don't know how it works'. (Interview 7) As a result even those who were sexually active were often unaware of the consequences of having sex:

they say - 'I've only had it once you know' and I say, 'you can get pregnant on once' and I'm amazed that they still think along them lines.

(Interview 1)

The staff thought this lack of awareness was surprising given all the media attention on the subject, and the amount of information that young people had access to:

You would think that they know everything about sex from what they read in magazines. It still surprises me how naïve, in spite of all this. (Interview 2)

Staff felt that the timing of sex education needed to be altered in schools, with information being provided at an earlier age, before girls began to embark on sexual experimentation:

cause you've lost 'em by the time they get to 12 you've lost a lot of them because they're already thinking along these lines.

(Interview 3)

Education about relationships was also lacking. Staff felt that this should include how to manage sex safely and enjoyably, how to have a relationship without having sex, or how to manage unwanted sexual advances. This leads on to the second area, assertiveness. Empowering young girls to be more assertive was, given the focus upon pressure and self-assertiveness arising through the interviews, not surprisingly identified as an education need:

How to empower them to manage relationships and that kind of thing.... How do they manage unwanted sexual advances? They never get information on that, or seem to get very little information on that.

(Interview 6)

It is trying to educate them that they are an individual, that they have got rights and there is things out there for girls

(Interview 2)

Helping them to recognise that the amount of peer pressure that might be around. If there isn't any peer pressure than ... its learning to recognise that here is peer pressure and then in resisting that.

(Interview 3)

To complete the interview, all participants were asked what issues they felt were important for future research investigations. Two themes were identified, and these echoed the content of the interviews. First, staff needed to understand why young girls wanted to have sex:

What do they think sex will do for them? (Interview 1)

What are their sexual expectations?

(Interview 4)

Why do they feel the need to be having sex?

(Interview 7)

The second related to understanding issues around pressure so that young girls can be helped to empower themselves. This in turn could help them to say no, if that is what they wanted to do:

How comfortable would they feel saying no?

(Interview 2)

How can we encourage them to be more assertive?

(Interview 7)

How can they overcome pressure without loosing face? 


\section{Discussion}

The purpose of the interviews was to provide background information to help plan a future study around young girls risk-taking behaviour. For this reason they were exploratory only. However, many of the issues arising from the interviews mirror those found in the research literature (Teenage Pregnancy Unit, 2000). Despite this, there were still areas which staff feel need to be explored further to enable them to understand why girls behave as they do, and thus provide a service tailored more to their needs.

A dominant theme in the present study related to the link between alcohol consumption and sexual behaviour. There is a large body of research which shows a link between the two (Mott and Haurin, 1988; Kowaleski-Jones and Mott, 1998; Bonomo et al., 2001). Wight et al. (2000) found at least $40 \%$ of 13-14 year olds who had had intercourse were 'drunk or stoned' the first time. Poulin and Graham (2001) found that unplanned sexual intercourse, whilst under the influence of alcohol, was found to be an independent risk factor for multiple sexual partners and inconsistent condom use in their sample of school pupils.

The strong link identified between alcohol consumption and sexual behaviour both in the present study, and the research literature in general, would suggest that this is a priority area to be addressed. Indeed the Teenage Pregnancy Report (1999: p. 74) recommends that sex education should 'make the links between education about sex and other related issues such as alcohol, smoking and drugs'. It was possibly surprising that whilst alcohol was identified as a major factor in young girls having unplanned sex in the present study, very little emphasis was placed by staff on the need for education around alcohol. Just one interviewee mentioned this as the way forward. Also of interest was how staff seemed to accept what they were told at face value in relation to this aspect (although not about the girls age), i.e., the girls got drunk and ended up having sex. Rhodes and Quirk (1995) suggest that being drunk provides a legitimate excuse for behaviour that might otherwise seem unacceptable. This could perhaps be the case especially for those girls as young as 11-14 years who might be concerned that they would be judged if they admitted that they chose to have sex. In contrast, alcohol consumption is seen as a natural part of growing up and thus might be perceived to be more socially acceptable than having underage sex. However, not one of the staff alluded to this possibility.

The identification of peer pressure as another reason for girls becoming sexually active at a young age also appears to be an issue for girls throughout the world (Rosenthal et al., 1996; Alexander and Hickner, 1997; Wight et al., 2000). This is particularly relevant for the younger age groups (Burrack, 1999). Dickson et al. (1998) also reported that women who first had intercourse under the age of 16 years were more likely to report the main reason to be that most people of their age were doing it.

There is a wide body of literature which looks at the link between self-esteem and early sexual activity. Whilst staff in the present study felt that many of their young clients lacked self-assertiveness and self-esteem, it is possible that this group of service users is actually atypical of their peers. Indeed Brook clients might actually be more self-assertive and confident than those girls who feel unable to access a sexual health service. Staff perceptions that low self-esteem meant that girls felt unable to challenge peer pressure are in agreement with findings from a number of other studies (Rosen and Ager, 1981; Holmbeck et al., 1994; Gardner et al., 1998; Kowaleski-Jones and Mott, 1998). However, others have found the opposite effect, namely that high self-esteem was an important predictor of early sexual intercourse (Morrison, 1985; Breakwell and Millward, 1997; Seal et al., 1997; Paul et al., 2000). Such contradictory findings suggest that further qualitative work with young girls is required to further understand the complex relationship between self-esteem and sexual behaviour.

The young girls' lack of knowledge around STIs, which emerged as a finding in the present study, has again been widely reported in the research literature (Nockels and Oakenstaff, 1999; Garside et al., 2001). Garside et al. (2001) found just one-third of 16-19 year olds recognized chlamydia as an STI and the little knowledge of STIs that was revealed was 'superficial'. However, most studies looking at young people's knowledge of STIs focus on those aged above 16 years, whilst there is a dearth of information focusing on the under 16 years. One of the few studies conducted with school pupils aged 13-15 years found that knowledge of STIs was poor, with just $18 \%$ of pupils in one of the three schools studied, having heard of gonorrhoea, 15\% chlamydia and 30\% syphilis (Magnusson et al., 2002). Just $44 \%$ of pupils in the same school knew 
that someone having an STI might not show signs or symptoms. In the recent report published by OFSTED (2002), education to prevent infection was reported as too often poor. However, the report stated that schools adequately covered the factual aspects of human reproduction. This was not a view shared by Brook staff, who felt that young girls were lacking in the knowledge around their own bodies and that the sex education should be provided at a younger age. Whilst it is possible that the young girls who access Brook had not yet received sex education, or had not attended school on days when it was taught, other studies would tend to endorse this view (Buston and Wight, 2002).

One finding that has emerged in the present study, but is not widely reported in the literature, relates to the phenomena that young girls have not known whether they have had intercourse or not. It is likely that this is not a new behaviour, given the wide acceptance that alcohol is a precipitating factor for sexual activity. Yet it might not have emerged as a well-documented research finding because the large body of research has concentrated on quantitative studies where the agenda is pre-determined. The studies have tended to identify links between early intercourse and a set of prescripted variables rather than look at the qualitative experience of early intercourse. The research methodology used in the few studies with very young girls might therefore not been instrumental in bringing this issue to light. Another suggestion to explain why this issue is not yet dominant in the literature might relate to the recent availability of emergency oral contraception. Young girls can now attend services for the emergency contraceptive pill as a precaution just in case they could be pregnant.

To conclude, staff perceptions around behaviour and needs of the early adolescent girl in the present study mirrors much of the research literature around young people in general. Although most of these issues have been widely documented in the research literature (with the exception of unknown sexual intercourse) there is little insight around the concepts and meanings of sexual risk taking behaviour for the young girls themselves. Staff at Brook identified the need to understand issues around peer and media pressure, self-esteem and the need young girls have to have sexual intercourse, from the young girls' perspective. Whilst not identifying this as an issue for future research, the interviews also illustrated staff difficulties around understanding why girls who did not enjoy sex continued to have intercourse. Again, this stems from their understanding of issues from an adult perspective rather than from the mindset of a 12-year old girl, for example. Therefore, the logical step forward is to work directly with the young girls themselves. The large body of quantitative research undertaken with young people of both sexes and all ages, and also adults working with them provides a background of useful information. Yet we still need the perspectives of the girls themselves to be able to start comprehending the situational and contextual factors which help to determine their sexual behaviour. This can only be undertaken by carrying out qualitative research which allows young girls to describe, explore and relate the issues of importance to them. This might help us, as adults to begin to understand the context of their behaviours, the choices they make, and thus be able to provide more appropriate education and services.

\section{Recommendations}

A number of recommendations have emerged from these interviews. These relate to two areas: education and research. Those around education in particular mirror current priorities documented in the Teenage Pregnancy Report (1999) and Sex and Relationship Education Guidance (DfEE, 2000).

\section{Sex education}

- To be provided in more depth and at an earlier age, i.e., before aged 12 .

- To include information on sexuality, relationships and STIs.

\section{Self-assertiveness education}

- How to recognize peer pressure

- How to say no and be comfortable about it

\section{Research}

Three topics have been identified for future research which should be carried out using qualitative methods to understand behaviour from the perspective of the young girl herself. These are:

- Understanding their experience of sex.

- The dynamics of peer and media pressure.

- Issues of self-esteem. 


\section{Acknowledgements}

The author would like to thank staff from the two Brook Advisory centres who took part in this project.

\section{References}

Alexander, E. and Hickner, J. 1997: First coitus for adolescents: understanding why and when. Journal of American Board of Family Practitioners 10, 96-103.

Blum, R.W., Beuhring, T., Wunderlich, M. and Resnick, M.D. 1996: Don't ask, they won't tell: the quality of adolescent health screening in five practice settings. American Journal of Public Health 86, 1767-72.

Bonomo, Y., Coffey, C., Wolfe, R., Lynskey, M., Bowes, G. and Patton, G. 2001: Adverse outcomes of alcohol use in adolescents. Addiction 96, 1485-96.

Breakwell, G.M. and Millward, L.J. 1997: Sexual self-concept and sexual risk-taking. Journal of Adolescence 20,29-41.

Brook Advisory. 2002: Teenage sexual activity. Factsheet 1, April. London: Brook Advisory Centres.

Burrack, R. 1999: Teenage sexual behaviour: attitudes towards and declared sexual activity. British Journal of Family Planning 24, 145-48.

Buston, K. and Wight, D. 2002: The salience and utility of school sex education to young women. Sex Education 2, 233-50.

De Gaston, J.F., Weed, S. and Jensen, L. 1996: Understanding gender differences in adolescent sexuality. Adolescence 31, 217-31.

Department for Education and Employment. 2000: Sex and relationship education guidance. London: Department for Education and Employment.

Dickson, N., Paul, C., Herbison, P. and Silva, P. 1998: First sexual intercourse: age, coercion, and later regrets reported by a birth cohort. British Medical Journal 316, 29-33.

Gardner, L.H., Frank, D. and Amankwaa, L. 1998: A comparison of sexual behavior and self-esteem in young adult females with positive and negative tests for sexually transmitted diseases. The ABNF Journal, 89-94.

Garside, R., Ayres, R., Owen, M.R., Pearson, V.H. and Roizen, J. 2001: They never tell you about the consequences: young people's awareness of sexually transmitted infections. International Journal of STD and AIDS 12, 582-88.

Holmbeck, G.N., Crossman, R.E., Wandrei, M.L. and Gasiewski, E. 1994: Cognitive development, ego centrism, self-esteem, and adolescent contraceptive knowledge, attitudes and behaviour. Journal of Youth and Adolescent 40, 254-63.

Kowaleski-Jones, L. and Mott, F.L. 1998: Sex, contraception and childbearing among high-risk youth: do different factors influence males and females? Family Planning Perspectives 30, 163-69.
Magnusson, J., Kendall, S., Townsend, J., Oakley, L., Gray, S., Crosti, J., Kilpin, S., Marshall, S., French, R. and Stephenson, J. 2002: Evaluation of the sexual health education team workshops in schools in Camden and Islington. Final Report. London: Camden and Islington Health Promotion Service.

Matocha, L.K. and Waterhouse, J.K. 1993: Current nursing practice related to sexuality. Research in Nursing and Health 16, 371-78.

Morrison, D.M. 1985: Adolescent contraceptive behaviour: a review. Psychological Bulletin 98, 538-68.

Mott, F.L. and Haurin, R.J. 1988: Linkages between sexual activity and alcohol and drug use among American adolescents. Family Planning Perspectives 20,128-36.

Nahom, D., Wells, E., Gillmore, M.R., Hoppe, M., Morrison, D.M., Murrowchick, E., Wilsdon, A. and Graham, L. 2001: Differences by gender and sexual experience in adolescent sexual behaviour: implications for education and HIV prevention. Journal of School Health 71, $153-58$.

Nockels, R. and Oakeshott, P. 1999: Awareness among young women of sexually transmitted chlamydia infection. Family Practitioner 16, 94.

OFSTED. 2002: Sex and relationships. 30 April. London: OFSTED Publication Office.

Paul, C., Fitzjohn, J., Herbison, P. and Dickson, N. 2000: The determinants of sexual intercourse before age 16 in a birth cohort. Journal of Adolescent Health 27, 136-47.

Pitts, M., Burtney, E. and Dobraszczyc, U. 1996: There is no shame in it any more: how providers of sexual health advice view young people's sexuality. Health Education Research: Theory and Practice 11,1-9.

Porter, C.P. 2002: Female 'tweens' and sexual development. Journal of Paediatric Nursing 17, 402-406.

Poulin, C. and Graham, L. 2001: The association between substance use, unplanned sexual intercourse and other sexual behaviours among adolescent students. Addiction 96, 607-21.

Rhodes, T. and Quirk, A. 1995: Drugs as 'reason' and 'excuse' for unsafe sex. Executive Summary, No. 40. London: Centre for Research on Drugs and Health Behaviour.

Rosen, R.H. and Ager, J.W. 1981: Self concepts and contraception: Preconception decision making. Population and Environment 4, 11-23.

Rosenthal, S.L., Lewis, L.M. and Cohen, S.S. 1996: Issues related to the sexual decision-making of inner city adolescent girls. Adolescence 31, 731-39.

Seal, A., Minichiello, V. and Omodei, M. 1997: Young women's sexual risk taking behaviour: re-visiting the influences of sexual self-efficacy and sexual self-esteem. International Journal of STD and AIDS 8, 159-65.

Social Exclusion Unit. 1999: Teenage pregnancy report. London: The Stationery Office.

Teenage Pregnancy Unit. September, 2000: Research to inform the national media campaign - teenage pregnancy in England. London: Teenage Pregnancy unit. 
Topolski, T.D., Patrick, D.L., Edwards, T.C., Huebner, C.E., Connell, F.A and Mount, K.K. 2001: Quality of life and health-risk behaviors among adolescents. Journal of Adolescent Health 29, 426-35.

Van den Akker., Lees, J.A. and Murphy, T. 1999: Adolescent sexual behaviour and knowledge. British Journal of Midwifery 7, 765-69.

Weber, R.P. 1990: Basic content analysis. Newbury Park, CA: Sage.
Wellings, K. 2001: Teenage sexual and reproductive behaviour in developed countries: country report for Great Britain. Occasional Report. No. 6. New York and Washington: The Alan Guttmacher Institute.

Wight, D., Henderson, M., Raab, G., Abraham, C., Burton, K., Scott, S. and Hart, G. 2000: Extent of regretted sexual intercourse among young teenagers in Scotland: a cross sectional survey. British Medical Journal 320, 1243-44. 